\title{
A estrutura do noema e a dupla concepção do objeto intencional em Husserl
}

\section{The Structure of Noema and the Dual Concepcion of the Intentional Object in Husserl}

*Carlos Diógenes Côrtes Tourinho

Resumo: O presente artigo aborda a especificidade do vivido intencional e a sua relação com as sensações não intencionais. Em seguida, examina a relação entre a noese e o noema, além de analisar a estrutura completa do noema. Mostra que o objeto intencional oscila entre o caráter imanente do noema e o que transcende o próprio noema. Ele traz como conclusão, então, que a análise da estrutura completa do noema evidencia uma dupla concepção do objeto intencional na subjetividade transcendental.

Palavras-chave: Edmund Husserl. Intencionalidade. Noese. Noema. Objeto intencional.

\begin{abstract}
This article discusses the specificity of the intentional experience and its relation with the non-intentional sensations. It examines the relationships between noese and noema and analyzes the complete structure of the noema, showing that the intentional object oscillates between the immanent character of the noema and somewhat that transcends the noema. It brings as a conclusions that the analysis of the complete structure of the noema shows a double concept of intentional object in transcendental subjectivity.
\end{abstract}

Keywords: Edmund Husserl. Intentionality. Noese. Noema. Intentional object.

\section{Introdução}

Pode-se dizer que, do ponto de vista fenomenológico, o tema da "vivência originária" assume, em Husserl, certas polaridades de

* Doutor em Filosofia pela PUC-RIO. Professor do Departamento de Filosofia e do Programa de Pós-Graduação em Filosofia da Universidade Federal Fluminense - UFF/Niterói-RJ. Membro do GT de Filosofia Francesa Contemporânea e Coordenador do GT de Fenomenologia da ANPOF.

\begin{tabular}{|l|l|l|l|l|l|}
\hline Veritas & Porto Alegre & v. 58 & n. 3 & set./dez. 2013 & p. 482-498 \\
\hline
\end{tabular}


suma importância para um aclaramento da estrutura da consciência transcendental, bem como do conjunto total dos elementos que compõem o vivido. Dentre essas polaridades, destaca-se, primeiramente, a dualidade entre a camada intencional do vivido e o substrato material a partir do qual tal camada atua, tornando a vivência uma vivência de alguma coisa. Trata-se de uma dualidade que coloca, de um lado, a camada material do vivido, isto é, os dados sensíveis que, enquanto "dados", nada designam, e de outro lado o ato intencional por meio do qual o vivido se "anima" de significação, tornando-se, então, designativo de um objeto. Apesar de nada designar, tais dados sensíveis não-intencionais apresentam-se no vivido como uma espécie de "substrato material" sem o qual a doação de sentido que parte do próprio ato intencional não começaria. Em termos mais precisos, tal dualidade pode ser expressa a partir da relação entre a "matéria" (hylé) e a "forma" (morphé) no vivido. Na medida em que adentramos na camada intencional do vivido e, portanto, na estrutura da consciência transcendental, deparamo-nos com uma outra polaridade, cujo foco das atenções concentra-se, segundo Husserl, em torno da relação entre a noese e o noema. O primeiro pólo dessa relação remetenos para o ato intencional propriamente dito, designando o conjunto total da vivência orientada subjetivamente, incluindo os próprios dados materiais enquanto informados pela intencionalidade. O segundo pólo remete, por sua vez, para a projeção dos dados hyléticos que, uma vez informados pela intencionalidade, são como se fossem "polarizados", em ordem à designação imediata do objeto. Trata-se, aí, do noema: a vivência orientada objetivamente. Por fim, se nos concentrarmos na estrutura do noema - mediador indispensável entre a noese e o "objeto" -, nós nos depararemos com uma dupla concepção do objeto intencional: a primeira remete para o que é imanente ao próprio noema, ao passo que a segunda remete para o que é visado pela noese por intermédio do noema. Tem-se, então, duas concepções do objeto intencional: uma imanente e outra transcendente ao noema. Tais oscilações do objeto intencional na subjetividade transcendental tornam-se uma parte delicada do projeto apresentado pela fenomenologia transcendental de Husserl. É o que o presente artigo examinará mais detalhadamente a partir de agora.

\section{A intencionalidade e a sua especificidade em Husserl}

Pode-se dizer que o conceito de "intencionalidade" assume, em Husserl, um papel crucial no projeto da filosofia fenomenológica. Como herança do pensamento de Brentano, Husserl retém a ideia básica segundo a qual a intencionalidade é a peculiaridade da experiência de ser consciente de alguma coisa. Husserl conservará, ao longo do seu percurso 
filosófico, o sentido primordial dessa intencionalidade em relação às vivências cognoscitivas ${ }^{1}$. Daí ele próprio afirmar, na "Quarta Lição" de A ideia da fenomenologia (1907), que: "As vivências de conhecimento possuem, isso pertence à sua essência, uma intentio, visam algo, se reportam de tal ou tal maneira a uma objetividade" 2 . Partindo dessa mesma suposição, Husserl definirá, no § 84 de Ideias I (1913), a intencionalidade como "a peculiaridade em virtude da qual as vivências são vivências de alguma coisa"3. E ainda, no § 14 de Meditações cartesianas (1931), o mesmo pensamento é apresentado novamente, porém, de um modo mais completo: "A palavra intencionalidade não significa outra coisa senão essa particularidade fundamental e geral da consciência de ser consciente de algo, de portar, em sua qualidade de cogito, o seu cogitatum nela mesma"4. Portanto, o conceito de "intencionalidade" irá se tornar um dos pontos fundamentais da teoria husserliana, sendo decisivo nos rumos do pensamento fenomenológico ${ }^{5}$. Husserl chegará mesmo a dizer, no § 84 de Ideias I (1913), que o referido conceito é um conceito inicial e fundamental, absolutamente indispensável no início da fenomenologia ${ }^{6}$.

O primeiro contato de Husserl com o referido conceito - cuja origem remonta à filosofia escolástica - se dá por intermédio dos cursos proferidos por Brentano, entre 1884 e 1886, na Universidade de Viena. É na obra de

1 A tradução das passagens da edição alemã das obras de Husserl citadas neste artigo é de minha autoria. Porém, no que se refere à tradução da edição alemã de Ideias I, recorremos, em certas passagens, ao auxílio da edição francesa da mesma obra, traduzida por Paul Ricoeur em 1950.

2 Cf. HUSSERL, E. Die Idee der Phänomenologie - Fünf Vorlesungen. Die Idee der Phänomenologie - Fünf Vorlesungen. In: Husserliana. Netherlands: Martinuos Nijhoff, Band II, 1950, p. 55.

3 Cf. HUSSERL, E. Ideen zu einer reinen Phänomenologie und phänomenologischen Philosophie. Erstes Buch: Allgemeine Einführung in die reine Phänomenologie. Halle a. d. S.: Verlag von Max Niemeyer, 1913, p. 168.

4 Cf. HUSSERL, E. Cartesianische Meditationen und Pariser Vorträge. In: Husserliana. Den Haag, Netherlands: Martinuos Nijhoff, Band I, 1973, p. 72.

5 Toda a fenomenologia seria, conforme nos lembra Føllesdal, um desdobramento desta noção. Cf. FØLLESDAL, D. "Edmund Husserl (1859-1938)". In: CRAIG, E. (ed.). Routledge Encyclopedia of Philosophy. London: Routledge, Vol. 4, 1998, p. 576. FRADIQUE MORUJÃO, A. "A doutrina da intencionalidade na fenomenologia de Husserl: das Investigações Lógica às Meditações Cartesianas". In: Idem. Estudos Filosóficos. Lisboa: Imprensa Nacional Casa da Moeda, Vol. 1, 2002, p. 6, chega a afirmar que a noção de "intencionalidade" torna-se o núcleo fundamental da teoria husserliana, ao ressaltar que: "A velha doutrina da intentio conhecida por Husserl através de Brentano, apresenta, na fenomenologia, um cariz completamente diferente. Em nosso entender, esta nova concepção da intencionalidade é o núcleo fundamental da teoria husserliana. A análise, sempre retomada, da noção do pensar intencional determina a evolução do pensamento do nosso autor".

6 Cf. HUSSERL, E. Ideen zu einer reinen Phänomenologie und phänomenologischen Philosophie, p. 171. 
São Tomás de Aquino que o filósofo alemão Franz Brentano (1838-1917) busca fundamentos para reeditar a questão da intencionalidade no último quarto do século 19. Para Tomás de Aquino, existir na natureza (esse naturale), que é como existem, para ele, as formas, é distinto de existir no pensamento (esse intentionale). Apoiando-se nesse segundo modo de existência, no qual as coisas existem no intelecto (in intellectu) enquanto "coisas pensadas", Brentano propõe uma teoria imanentista da intencionalidade, segundo a qual o ato de ser intencional deve ser definido como "ser objetivo em sentido imanente", o que equivale a dizer que todo ato mental contém em si algo como seu objeto.

Na obra de Tomás de Aquino, particularmente, em Quaestiones disputatae de veritate (Quaestio prima), deparamo-nos com algumas considerações importantes sobre o tema em questão. Logo no Artigo Primeiro da referida obra, Tomás de Aquino afirma que, residindo no próprio intelecto, a conformidade com as coisas pressupõe tanto a possibilidade de apreensão das coisas (que estariam fora da alma) mediante imagens, como a formação de juízos verdadeiros, conforme o modo característico da inteligência que conhece (modum cognoscentis). Para Tomás de Aquino, as coisas criadas existiriam, portanto, de dois modos distintos: na natureza ou "fora da alma" (extra animam) e "no intelecto" (in intellectu). É nesse segundo modo que encontramos a ideia de uma "in-existência" da coisa no intelecto, a coisa segundo o modo de existência de "coisa pensada" (secundum esse quod habet in intellectu). Inspirando-se nesse segundo modo de existência, Brentano reedita, no último quarto do século 19, uma teoria imanentista da intencionalidade, segundo a qual o objeto do pensamento "in-existe" como tal no próprio pensamento.

Em sua obra de 1874, intitulada Psicologia do ponto de vista empírico, Brentano busca, basicamente, um critério de demarcação que permita o estabelecimento de uma distinção entre os fenômenos físicos e os fenômenos mentais. No primeiro capítulo do Livro II, Brentano afirma que: "Todos os dados da consciência são divididos em duas grandes classes - a classe do fenômeno físico e a classe do fenômeno mental"7. Ainda no mesmo capítulo, Brentano introduz o que considera ser a característica que melhor permite distinguir os fenômenos mentais dos fenômenos físicos: trata-se da relação intencional entre atos mentais e seus objetos. A ideia central de Brentano é a de que os fenômenos mentais são atos mentais dirigidos (ou voltados) intencionalmente para os seus objetos. Em princípio, tais objetos são fenômenos físicos, porém,

Cf. BRENTANO, F. Psychology from an Empirical Standpoint. London: Routledge \& Kegan Paul, 1973, p. 77. 
os fenômenos mentais (ou "atos mentais") podem também se tornar objetos de outros atos mentais. A relação entre fenômenos mentais e fenômenos físicos é, portanto, uma relação intencional entre atos mentais e seus objetos. Brentano irá caracterizar essa relação a partir de uma reedição da concepção aristotélico-tomista de "in-existência intencional" de um objeto. Trata-se, aí, de uma "in-existência" não no sentido de "não existir", mas no sentido de "existir em", sugerindo, portanto, um modo de relação de imanência entre o ato intencional e o seu objeto. Após cair em desuso no Renascimento e na Modernidade, essa terminologia foi, então, revivida por Brentano, usada para veicular a ideia segundo a qual o objeto do pensamento in-existe como tal no próprio pensamento. Eis a definição do termo "intencionalidade" na filosofia de Brentano: "ser objetivo em sentido imanente", o que equivale a dizer que todo fenômeno mental contém em si algo como seu objeto (ou o seu conteúdo). O campo fenomenal se abre revelando, em sua imanência, a referência intencional aos objetos.

No que se refere à originalidade de Husserl no encaminhamento do referido conceito, nota-se, sobretudo, a partir de 1907, em A ideia da fenomenologia, que as investigações em torno da intencionalidade não habitariam mais o domínio do que é meramente empírico e, definitivamente, não estariam mais voltadas para a ideia de uma "objetividade imanente" (no sentido proposto por Brentano no último quarto do séc. 19), nem tampouco para o problema de como é possível uma vivência intelectiva intentar algo que se encontra fora do seu próprio domínio. Ao suspender o juízo em relação à facticidade do mundo, a fenomenologia promoverá, a partir da redução fenomenológica, o salto do domínio do que é transcendente (no sentido do que não é autoevidente) para o domínio de uma autêntica imanência (de uma claridade absoluta, do dar-se em si mesmo), fazendo com que o fenômeno puro se revele imediatamente para uma consciência doadora de sentido. Recupera-se a concepção aristotélico-tomista da intencionalidade como "objetividade imanente", porém, para pensá-la agora no plano transcendental. O mundo reduzido será, então, considerado apenas como significado e, portanto, apresenta-se como mero corolário da consciência pura que o significa, adquirindo assim um caráter absoluto. Amplia-se a esfera de investigação em torno da intencionalidade, cabendo agora examinar os elementos que, no ato intencional da consciência pura, são responsáveis pela constituição das diferentes modalidades do "aparecer" enquanto tal (diferentes formas do dar-se dos objetos na consciência pura). O problema da intencionalidade aparece, a partir desse momento, intimamente associado à ideia da "constituição dos objetos" na consciência transcendental. Diferentemente de Brentano, para quem 
a relação intencional ainda se mantinha em uma dimensão meramente psicológica, Husserl procurou situar, através da redução fenomenológica, a intencionalidade em uma região transcendental, independente de - e anterior a - toda descrição psicológica, recuperando, assim, de um modo original, a idéia de "objetividade imanente".

\section{O vivido intencional e a sua relação com os dados não-intencionais}

Tratar-se-á, portanto, com a intencionalidade, de uma propriedade essencial da consciência transcendental cuja presença "vivifica" a vivência, tornando-a designativa de um objeto. No § 36 de Ideias I (1913), Husserl afirma que é da essência de todo cogito atual "ser consciência de algo", de tal modo que todos os vividos que possuem tal propriedade são chamados de "vividos intencionais" (ou "atos intencionais", se optarmos por um termo adotado à época das Investigações lógicas), uma vez que tais vividos são "consciência de algo". Pode-se dizer que são "intencionalmente referidos" a esse algo ${ }^{8}$. Porém, para Husserl, nem todas as vivências (ou atos) são intencionais. Trata-se de uma constatação para a qual Husserl já chamava a atenção desde as Investigações lógicas $(1900 / 1901)^{9}$, afirmando, no § 10 da V Investigação, que existem "atos não intencionais". Husserl cita como exemplo de atos não intencionais as próprias sensações, afirmando, no referido parágrafo: "Que nem todas as vivências sejam intencionais, mostram-nos as sensações e complexos sensacionais" ${ }^{10}$. No § 11 da mesma V Investigação, procurando exemplificar atos do tipo "não intencional", faz ainda a seguinte colocação: "Não vejo impressões de cores, mas coisas coloridas; não ouço impressões de sons, mas a canção cantada, etc" ${ }^{11}$. Portanto, para Husserl, novamente, nos termos de Ideias I (1913), por "vivência", devemos entender tudo aquilo que se pode encontrar no fluxo de vividos em geral:

8 Cf. HUSSERL, E. Ideen zu einer reinen Phänomenologie und phänomenologischen Philosophie, p. 64.

9 Ainda que o próprio Husserl especificasse, em um manuscrito de 1907, que, de certo modo, as Investigações ainda faziam com que a fenomenologia passasse por uma "psicologia descritiva", sem que se distinguisse nitidamente uma fenomenologia meramente empírica da consciência de uma fenomenologia transcendental. O manuscrito (Setembro de 1907, B II 1) é citado por Walter Biemel no texto de apresentação à edição alemã das "Cinco Lições". Cf. HUSSERL, E. Die Idee der Phänomenologie - Fünf Vorlesungen. Die Idee der Phänomenologie - Fünf Vorlesungen, p. IX.

10 Cf. HUSSERL, E. Logische Untersuchungen - Zweiter Band, Erster Teil: Untersuchungen zur Phänomenologie und Theorie der Erkenntnis. Halle a. d. S.: Max Niemeyer, 1913, p. 369.

11 Ibid., p. 374. 
[...] não apenas por conseguinte os vividos intencionais, as cogitationes atuais e potenciais tomadas em sua plena concreção, mas todos os momentos reais (reellen) suscetíveis de serem descobertos neste fluxo e em suas partes concretas ${ }^{12}$.

O conceito de "vivência" remete-nos, então, no § 36 de Ideias I (1913), para o fluxo de vividos em geral, englobando tanto os vividos desse fluxo que possuem a propriedade de "ser consciência de algo", quanto os "momentos reais" que, por serem apenas dados, nada designam ainda e, portanto, encontram-se desprovidos de tal propriedade intencional, tais como os "dados de sensação" (Empfindungsdaten), os dados de cor, de tato, de som e semelhantes. Husserl ilustra-nos, no mesmo § 36 de Ideias I (1913), a presença desses momentos não intencionais, bem como a relação entre os mesmos e a intencionalidade no fluxo de vividos, dando-nos como exemplo o vivido da percepção do papel branco. Nele, deparamonos com o dado de sensação "branco", dado esse que, segundo Husserl, pertence inseparavelmente à essência da referida percepção, enquanto seu componente real. "Como conteúdo exibidor do branco do papel que aparece, ele é suporte [Träger] de uma intencionalidade, mas não é ele mesmo uma consciência de algo"13. O mesmo vale, segundo Husserl, para outros dados de vivido, por exemplo, os chamados "sentimentos sensíveis" (sinnlichen Gefühlen).

No parágrafo § 85 de Ideias I (1913), Husserl retoma o tema em questão, destacando que, no fluxo de vividos, além da "camada intencional" que "anima" a vivência de significações, tornando-a designativa de um objeto -, todo vivido possui um "substrato" sensível e, como vimos, "não intencional". Segundo Husserl, tal substrato - na medida em que é suporte para uma intencionalidade - se torna uma peça importante para o entendimento da trama que envolve a formação intencional (ou as doações de sentido de diferentes níveis) no vivido como um todo. A "camada intencional" age sobre os momentos sensíveis, "animando-os", dando-lhes sentido (sinngebende). Trata-se, segundo Husserl, de uma camada por meio da qual o próprio vivido intencional se realiza, "[...] a partir do elemento sensual que em si nada tem de intencional"14. Vê-se que a cogitatio é decomposta em duas partes: os momentos sensíveis (não intencionais) e a camada intencional. Apesar dessa dualidade, Husserl não deixa de enfatizar o laço que os une, uma vez que, no vivido como

12 Cf. HUSSERL, E. Ideen zu einer reinen Phänomenologie und phänomenologischen Philosophie, p. 65.

13 Ibid.

14 Ibid., p. 172. 
um todo, os dados sensíveis seriam como a "matéria" (que nada tem de intencional, mas que serve de "substrato" para a formação intencional), ao passo que a camada intencional seria como a "forma" (cujo papel no vivido seria propriamente o de promover a doação de sentido). Ainda que essa doação de sentido não derive da matéria, não começa sem ela, pois é sobre a matéria que a camada intencional agirá, atribuindo-lhe significação.

Em todo vivido em geral, essa dualidade e essa unidade observável da hylé sensual e da morphé intencional representarão um papel importante. Nos termos de Husserl, no § 85 de Ideias I (1913), "Dados sensíveis se dão como matéria para formações intencionais ou doações de sentido de diferentes níveis [...]"15. Tais "dados sensíveis" - substrato da intencionalidade - recebem, em Husserl, o nome de "dados hiléticos" (ou materiais), ao passo que o que introduz no vivido a especificidade da intencionalidade recebe o nome de "momento noético" (noetisches Moment) ou pura e simplesmente noese. Segundo Husserl, a noese constitui o que é específico do noûs no sentido mais amplo da palavra, remetendo-nos para as cogitationes e os vividos intencionais em geral e, portanto, para uma de suas significações mais eminentes: a "doação de sentido" ${ }^{16}$. Por fim, Husserl conclui o $\$ 85$ de Ideias I (1913), afirmando que o fluxo dos vividos ("o fluxo do ser fenomenológico") possui uma "camada material" e uma "camada noética". A consideração e análise fenomenológica cuja atenção se concentra especificamente em torno dos dados hiléticos (ou materiais) poderá ser chamada de hiléticofenomenológica, ao passo que a consideração referente aos momentos noéticos poderá ser chamada de noético-fenomenológica. Husserl deixa claro que, das duas modalidades de análise fenomenológica, a mais importante e incomparavelmente mais rica se encontra do lado noético ${ }^{17}$.

No § 86 de Ideias I (1913), Husserl destaca ainda mais a importância da análise noético-fenomenológica, ao chamar a atenção para a relevância assumida pelos chamados "problemas funcionais": problemas referentes à "constituição das objetividades da consciência". Tais problemas dizem respeito ao modo como as noeses - animando o material e entrelaçandose em conteúdos e sínteses unificadoras do diverso (man-nigfaltigeinheitlichen) - produzem consciência "de" alguma coisa ${ }^{18}$. Husserl esclarece, então, que, quando nos referimos aos "problemas funcionais", o termo "função" assume um sentido bem singular, fundado na essência

15 Cf. HUSSERL, E. Ideen zu einer reinen Phänomenologie und phänomenologischen Philosophie, p. 172-173.

16 Ibid., p. 174.

17 Ibid., p. 175.

18 Ibid., p. 176. 
pura das noeses: na doação de sentido que "vivifica o vivido". Portanto, o referido termo assume um sentido diferente daquele a que lhe é atribuído pela matemática. O ponto de vista funcional torna-se, assim, segundo Husserl, central para a fenomenologia, concentrando-se em torno do modo como unidades objetivas se "constituem para a consciência". Novamente, Husserl chama a atenção para a primazia das considerações e análises noético fenomenológicas sobre a análise hilética: "Naturalmente, a hilética pura se subordina à fenomenologia da consciência transcendental"19. Apesar de tal primazia, Husserl alerta para o fato de que a própria hilética - concebida com uma disciplina autônoma e, como tal, dotada de um valor em si própria - assume, do ponto de vista funcional, a sua importância, uma vez que proporciona "[...] uma trama possível no tecido intencional, uma matéria possível para formações intencionais" 20 . Seja como for, na visão de Husserl, ela se encontra, não somente pela dificuldade, mas também pela hierarquia de problemas relativos à ideia de um conhecimento absoluto, bem abaixo da fenomenologia noética.

\section{A estrutura do noema: núcleo noemático e caracteres noemáticos}

Ainda no que se refere à estrutura da consciência transcendental, Husserl apresenta uma outra polaridade, cujos pólos da relação passam a ser denominados de noese e noema. Trata-se de duas palavras de origem grega que podem ser traduzidas por "inteligência" ou "compreensão". As terminações destas palavras sugerem, contudo, respectivamente, "ação" e "termo da ação". Por isso, Husserl optou pelo termo noese para designar a vivência no seu caráter mais tipicamente "atual" ou "subjetivo", enquanto que a opção pelo termo noema se dá para indicar o aspecto "objetivo" da vivência, só inteligível como consequência do anterior ${ }^{21}$.

$\mathrm{O}$ ato intencional da consciência pura - na medida em que "anima" (ou informa) os dados materiais - é a noese propriamente dita. O mesmo termo será utilizado para designar o conjunto total da vivência orientada subjetivamente, incluindo os próprios dados materiais enquanto informados pela intencionalidade. Nos termos do § 85 de Ideias I (1913): "O que informa [formt] a matéria para fazer dela um vivido intencional, o

19 Cf. HUSSERL, E. Ideen zu einer reinen Phänomenologie und phänomenologischen Philosophie, p. 178.

20 Ibid.

${ }^{21}$ Sobre a etimologia dos termos noese e noema, cf. FRAGATA, J. A fenomenologia de Husserl como fundamento da filosofia. Braga: Livraria Cruz, 1956, p. 134. 
que introduz o elemento específico da intencionalidade [...]"22. Uma vez informados pela intencionalidade e, portanto, tornando-se "intencionais", os dados hiléticos são projetados, como se fossem "polarizados", em ordem a designação imediata do objeto. Nessa "polarização", serão caracterizados como "noemáticos". Eis, então, o noema: a vivência orientada objetivamente.

O § 88 de Ideias I (1913) anuncia, no vivido, uma "distinção fundamental que concerne à intencionalidade", qual seja, a distinção entre os componentes propriamente ditos dos vividos intencionais e os seus correlatos intencionais ${ }^{23}$. Tal distinção remete, mediante uma análise do vivido, para a oposição recíproca entre noese e noema. Com os seus "elementos materiais" enquanto dados, a noese constitui a parte "real" (reell) ou intrínseca do vivido. Já o noema - com os elementos materiais enquanto "projetados" - transcende, em certo sentido, a vivência na medida em que é uma "projeção" da mesma, não pertencendo aos seus constituintes "reais". Husserl afirma, então, no mesmo § 88, que o noema é o componente "não real" ou "intencional", uma vez que "tende" para o "objeto" que designa ${ }^{24}$. É graças ao noema que o objeto adquire, em sua versão reduzida, uma presença imanente diversa, ao mesmo tempo, da consciência que se tem dele. Ao considerarmos o objeto como "conteúdo intencional" da consciência, atingimos o "fenômeno" no sentido mais próprio e característico da fenomenologia transcendental. E como nos diz Husserl, ao final do § 88: "[...] nós podemos descrever fielmente e com uma perfeita evidência 'o que aparece como tal'" 25 .

Para que haja uma elucidação ainda maior do "objeto intencional" - a "coisa visada" em sua doação originária, tal como se apresenta na esfera da consciência transcendental -, torna-se imprescindível um aclaramento da estrutura completa do noema, constituída, segundo Husserl, por elementos que fazem parte do "núcleo noemático" e dos "caracteres do noema". No "núcleo noemático" (noematischer Kern), deparamo-nos com o elemento responsável pela designação do sentido objetivo do que é intencionado, ao passo que nos "caracteres noemáticos" (noematische Charaktere), deparamo-nos com os elementos que não estão orientados para tal designação, mas apenas remetem para o modo como temos consciência do que é intencionado (enquanto objeto de uma "recordação", de uma "imaginação", de um "juízo", etc.).

22 Cf. HUSSERL, E. Ideen zu einer reinen Phänomenologie und phänomenologischen Philosophie, p. 174.

23 Ibid., p. 181.

24 Ibid.

25 Ibid., p. 183. 
Os "caracteres noemáticos" - tal como uma "camada externa" ou "periférica" do noema - não determinam, portanto, o sentido objetivo daquilo que se intenciona (o objeto intencional idêntico), mas caracterizam o que é intencionado apenas no seu modo de se apresentar (in Wie seiner Gegebenheitsweise). Sendo assim, tais caracteres noemáticos podem variar, ainda que permaneça idêntico o objeto intencionado. Com essa variação, o mesmo objeto poderá se apresentar como existindo realmente ou duvidosamente, em uma percepção ou em uma imagem, e assim por diante. Husserl afirma, no $\S 130$ de Ideias I, que tais caracteres noemáticos não pertencem ao objeto - de que se tem consciência -, mas ao modo como se tem consciência dele ${ }^{26}$.

Já o "núcleo noemático" é o conteúdo da estrutura do noema responsável por manter idêntico o objeto, por determiná-lo em seu "sentido objetivo" (gegenständlicher Sinn), a despeito das variações dos caracteres noemáticos. Como nos diz Husserl, ao final do § 130 de Ideias I (1913), torna-se evidente que um "estatuto" (Gehalt) inteiramente invariável seja delimitado na estrutura de cada noema, mais precisamente, em seu "núcleo noemático". No mesmo parágrafo, afirma ainda que: "Toda consciência tem o seu o quê e tudo o que é visado tem a 'sua' objetividade" 27 . Esse aspecto, determinado pelo conteúdo do noema referente ao "núcleo noemático", é a parte central da estrutura completa do noema.

Ao analisar a estrutura completa do noema, Husserl afirma, então, em um primeiro momento, que tal estrutura é composta por elementos que fazem parte do "núcleo noemático" e dos "caracteres do noema" (na linguagem das Investigações lógicas, particularmente, da "V Investigação", o "núcleo noemático" corresponderia à "matéria" do ato intencional, ao passo que os "caracteres noemáticos" seriam equivalentes à "qualidade" do referido ato) ${ }^{28}$. Como vimos, se os últimos remetem para o modo de apresentação do que é intencionado na consciência, variando no cogito as diferentes modalidades de aparecimento do cogitatum (ora como objeto de uma lembrança, ora como objeto de um juízo, etc.), o "núcleo noemático" é, de certo modo, o conteúdo "invariável" do noema, uma vez que determina o sentido objetivo do que é intencionado no cogito, fazendo com que o cogitatum trazido à consciência se mantenha idêntico a despeito das variações no seu modo de apresentação.

${ }^{26}$ Cf. HUSSERL, E. Ideen zu einer reinen Phänomenologie und phänomenologischen Philosophie, p. 270.

27 Ibid.

${ }_{28}$ Tal correspondência aparece assinalada por Husserl no § 129 de Ideias I; cf. ibid., p. 268. 
No entanto, em um esclarecimento posterior, no § 131 de Ideias I (1913), Husserl afirma que o "sentido objetivo" também pode variar e, ainda assim, significar o mesmo objeto. Nos termos do autor:

Nós podemos dizer então: vários noemas de atos têm aqui diferentes núcleos, mas de tal modo que estes convergem numa união de identidade, numa unidade na qual o 'algo', o determinável que reside no núcleo, é trazido à consciência como idêntico ${ }^{29}$.

O "sentido objetivo" constitui, portanto, o objeto ainda no seu como, embora já determinado através de predicados que só a ele convêm. Em oposição aos "caracteres do noema" (responsáveis por caracterizar o objeto "no seu modo de presença"), o "sentido objetivo" caracteriza-o já no como das suas determinações (in Wie seiner Bestimmtheiten). Porém, não estamos ainda perante o objeto simplesmente considerado. Os predicados ou as determinações que constituem o "sentido objetivo" variam segundo as diferentes perspectivas, permanecendo, no entanto, como síntese de todas as variações, um "objeto idêntico" (afinal, os predicados são predicados de "alguma coisa"). Nos termos de Husserl: "Através do progresso contínuo ou sintético da consciência, o objeto intencional apresenta-se sempre consciente; mas não cessa de se dar 'de outra forma'; é 'o mesmo' objeto, dado simplesmente em outros predicados, com outros elementos determinantes" 30 .

Portanto, em um primeiro momento, Husserl nos chama a atenção para a variação referente aos "caracteres do noema" (variando no cogito as diferentes modalidades de aparecimento do cogitatum), apontando o "núcleo noemático" como o conteúdo invariável do noema (responsável por determinar o sentido objetivo do que é intencionado no cogito, fazendo com que o cogitatum se mantenha idêntico a despeito das variações no seu modo de apresentação); já em um segundo momento, como vimos na citação acima, no § 131 de Ideias I (1913), Husserl atenta para a possibilidade de se pensar variações referentes ao próprio "núcleo noemático", no sentido de que podemos pensar diferentes núcleos noemáticos correspondentes a diferentes atos de pensamento (em cada cogito, teríamos um núcleo), convergindo em torno de uma unidade na qual o "algo" determinável nos núcleos seria trazido à consciência como "idêntico". Husserl afirma, então, que atos separados - por exemplo, duas percepções ou uma percepção e uma lembrança - poderiam convergir em uma unidade concordante, trazendo à consciência aquilo que é

${ }^{29}$ Cf. HUSSERL, E. Ideen zu einer reinen Phänomenologie und phänomenologischen Philosophie, p. 271.

30 Ibid. 
determinado como o mesmo algo intencionado, o objeto idêntico por concordância dos diferentes atos intencionais. Nos termos de Husserl, trata-se do mesmo objeto, porém, "[...] dado simplesmente em outros predicados, com um outro estatuto de determinação" ${ }^{31}$. Nesse sentido, cabe notar que, para Husserl, o "objeto" idêntico em torno do qual se agregam os diferentes atos se distingue, com evidência, dos "predicados" variáveis atribuídos por cada um dos atos. Desse modo, tal "objeto idêntico" é, para Husserl, o "momento noemático central". Trata-se de um "puro X", do "objeto simplesmente considerado" (der Gegenstand schlechthin), obtido por abstração de todos os seus predicados, dos quais se distingue enquanto um ponto de junção ou "suporte" dos mesmos ${ }^{32}$.

Portanto, se as variações dos "caracteres noemáticos" - anunciadas por Husserl em um primeiro momento - deixam transparecer o sentido idêntico designativo do objeto (fazendo com que o cogitatum se mantenha idêntico a despeito das variações no seu modo de apresentação), da mesma forma, por meio das variações dos predicados constitutivos desse sentido, se destaca, por abstração dos predicados atribuídos por cada um dos atos, aquilo que é invariável e central, determinável por esses mesmos atos. Segundo Husserl, nenhum objeto é pensável sem que seja, igualmente, pensável uma multiplicidade de vividos intencionais, cada um dos quais ligados segundo uma unidade continua, no sentido de que o objeto é apreendido pela consciência enquanto "idêntico", ainda que sob um modo diferente do ponto de vista noemático. Sendo assim, os núcleos correspondentes aos atos são variáveis, porém, o "objeto" em torno do qual se agregam tais atos - "o puro sujeito dos predicados", para usar a terminologia de Husserl - é precisamente trazido à consciência como "idêntico". Sendo assim, o § 131 de Ideias I (1913) revela que a análise completa da estrutura do noema remete, na consciência transcendental, para duas concepções de objeto: o "objeto puro e simples" (o "puro X" determinável no núcleo por abstração de seus predicados, em torno do qual convergem os diferentes núcleos dos diferentes atos); e o "objeto no como de suas determinações" (dado em outros predicados, cada um dos quais com um outro estatuto de determinação).

\section{A dupla concepção de "objeto intencional"}

A dupla concepção de "objeto" - revelada pela análise da estrutura completa do noema, particularmente, do "núcleo noemático", a partir

${ }^{31}$ Cf. HUSSERL, E. Ideen zu einer reinen Phänomenologie und phänomenologischen Philosophie, p. 271.

32 Ibid. 
das considerações do § 131 de Ideias I (1913) - irá impor uma nova versão da "transcendência na imanência", apontando-nos, com isso, um novo deslocamento do "transcendente". Em Husserl, as variações do "transcendente" deslocam, como resultado da radicalização da epoché, de uma "objetividade transcendente" - dirigida inicialmente para o que se encontra fora da vivência intelectiva, dirigida para o ser sob modo de "coisa natural" (extra anima) - para uma autêntica "objetividade imanente" dentro da qual o objeto se encontra, em sua versão reduzida, como um conteúdo intencional da consciência, apreendido e constituído intuitivamente. Portanto, tais variações levam para uma "transcendência da imanência". Se o transcendente é, em Husserl, em um primeiro momento, fonte de dúvidas e de incertezas, em um segundo momento, a transcendência para a qual a redução fenomenológica nos desloca a atenção é a da própria "coisa" em sua doação originária, apreendida e constituída intuitivamente, na autêntica imanência da subjetividade transcendental. Tal variação do transcendente em Husserl desloca, então, a atenção para a "autêntica objetividade imanente", domínio último de evidenciação sobre o qual a fenomenologia transcendental concentrará o foco de suas investigações. Quando pensamos o objeto como o "puro X" determinável no núcleo noemático por abstração de seus predicados, em torno do qual convergem os diferentes núcleos dos diferentes atos, estamos pensando esse "puro X" como uma peculiar "transcendência na imanência" do próprio núcleo noemático. Distinguindo-se do núcleo, tal objeto ocupa um ponto particularmente íntimo do noema, formando a "parte central do núcleo".

Por outro lado, Husserl chama-nos a atenção, ao final do § 129 de Ideias $I$ (1913), para um certo "paralelismo" entre a noese e o noema e entre esse último e o objeto, entendendo agora o "objeto" não como a "parte íntima" do núcleo noemático, mas como algo visado pela noese por meio do noema e, desse modo, como algo "transcendente ao noema", porém, na subjetividade transcendental. Husserl afirma que a distinção entre "conteúdo" e "objeto" - introduzida por Twardowski ${ }^{33}$ - se impõe não

33 Uma das principais contribuições do filósofo polonês Kazimierz Twardowski (1866-1938) consiste em ter acrescentado à distinção entre ato mental e seu objeto um terceiro elemento: o conteúdo desse ato. Se em Brentano as noções de "objeto" e de "conteúdo" imanente de um ato mental são equivalentes, com Twardowski, essas noções serão concebidas separadamente. Em sua dissertação de Habilitation, intitulada Zur Lehre vom Inhalt und Gegestand der Vorstellungen (Sobre a doutrina do conteúdo e objeto das representações), escrita em 1894, Twardowski fornece, no § 6, uma análise detalhada da distinção entre conteúdo e objeto no caso das "representações" (Vorstellungen). O autor apresenta três argumentos principais para o estabelecimento desta distinção: (1) conteúdos e objetos não podem ser idênticos, uma vez que, por vezes, juízos verdadeiros que negam a existência de objetos são baseados em representações; nesses casos, 
apenas para a consciência (ou para o vivido intencional), mas também para o noema. Por conseguinte, lembra Husserl, o noema também se refere a um objeto e possui um conteúdo, "por intermédio" do qual se refere ao objeto. Daí ele próprio dizer, no § 129 de Ideias I (1913): "Todo noema tem um 'conteúdo', nomeadamente, o seu 'sentido', e por meio dele, se refere a 'seu' objeto" ${ }^{34}$. Tal objeto é, por sua vez, o mesmo objeto visado pela noese. Donde se confirma integralmente, segundo Husserl, o paralelismo entre noese-noema e noema-objeto ${ }^{35}$.

No sentido trazido pelo § 129 de Ideias I (1913), "o noema transcende a noese e o objeto transcende o noema". Tudo isso, na subjetividade transcendental. Daí talvez, por esse motivo, Husserl afirmar, no § 16 de Ideias III (1952) ${ }^{36}$, que: "o noema [...] não é nem contém a essência da coisa" ${ }^{37}$, pois o "objeto" encontra-se no noema apenas como "significado", de modo que aquilo que significa (noema) distingue-se do que se significa ("objeto"). Apesar de transcender o noema, o objeto é, tal como considerado no § 129 de Ideias I (1913), imanente à subjetividade transcendental (no sentido mais amplo, é também uma "transcendência

o conteúdo existe, o objeto não; (2) conteúdos possuem propriedades que não se encontram nos objetos e vice-versa; por exemplo, uma montanha de ouro tem, entre outras, a propriedade de ser espacialmente estendida, de se compor de ouro, de ser maior ou menor que outras montanhas, etc. Essas propriedades e relações de grandeza com outras montanhas não se aplicam obviamente ao conteúdo da representação de uma montanha de ouro, pois o conteúdo não é espacialmente estendido, nem tampouco podemos aplicar a ele enunciados sobre relações de grandeza; (3) há o caso em que conteúdos de representações não equivalentes se referem a um mesmo objeto; por exemplo, "a cidade localizada em Roman Juvavum" e "o lugar em que nasceu Mozart". Tais representações se distinguem quanto ao seu conteúdo, ainda que se refiram ao mesmo objeto. Cf. TWARDOWSKI, K., Zur Lehre vom Inhalt und Gegestand der Vorstellungen. Eine psychologische Untersuchung. München-Wien: Philosophia Verlag, 1982, § 6. Twardowski afirma que o objeto de um ato mental não é, conforme propusera Brentano, "imanente" ao ato, quer dizer, não é uma parte daquele ato. Além disso, insiste em ressaltar que a questão quanto ao ato mental ter ou não um objeto deve ser distinguida da questão concernente a um objeto existir ou não. Twardowski defenderá a tese segundo a qual, muito embora todo ato mental tenha um objeto (ou intenção), muitos desses objetos não existem ou não são reais. A dissertação de Habilitation de Twardowski possui uma significação histórica considerável; afinal, trata-se de uma obra cujas influências recairão sobre a teoria geral dos objetos em Meinong e sobre teoria da intencionalidade de Husserl, ainda que esse último tenha criticado Twardowski por seu psicologismo.

34 Cf. HUSSERL, E. Ideen zu einer reinen Phänomenologie und phänomenologischen Philosophie, p. 267.

${ }^{35}$ Ibid., p. 269.

36 A primeira edição de Ideias III foi publicada em 1952 (volume V da Husserliana). A edição com a qual trabalhamos data do ano de 1986 (conferir as Referências).

37 Cf. HUSSERL, E. Ideen zu einer reinen Phänomenologie und phänomenologische Philosophie. Drittes Buch: Die Phänomenologie und die Fundamente der Wissenschaft. In: Husserliana. Hamburg: Felix Meiner Verlag, Band V, 1986, p. 87. 
na imanência"). Da primeira para a segunda concepção de objeto, desloca-se, em relação ao noema, de uma nova versão da "transcendência na imanência" (o "puro X" que, apesar de ser determinável no núcleo, distingue-se do núcleo) para a transcendência no sentido do que não é intrínseco ao noema (daquilo que é visado pela noese por meio do noema, mas que, no entanto, encontra-se "fora" do noema). Porém, tudo isso, na subjetividade transcendental. Tais concepções de "objeto" impõem, portanto, em relação ao noema, de forma correlativa, novas versões do transcendente em Husserl. O "objeto intencional" oscila, por sua vez, entre o caráter imanente do noema e o que transcende o próprio noema. Eis um ponto particularmente delicado que a análise da estrutura completa do noema acaba por revelar no projeto filosófico anunciado por Husserl: a dupla concepção do "objeto intencional" na subjetividade transcendental. Os escritos de Husserl deixam, então, o desafio de elaborar um esquema por meio do qual seja possível conciliar tais concepções oscilantes do objeto intencional. Uma consideração mais detalhada acerca das dificuldades impostas por esse desafio ficará, porém, para uma outra ocasião.

\section{Referências}

BRENTANO, F. Psychology from an Empirical Standpoint. London: Routledge \& Kegan Paul, 1973.

FØLLESDAL, D. "Edmund Husserl (1859-1938)". In: CRAIG, E. (ed.). Routledge Encyclopedia of Philosophy. London: Routledge, Vol. 4, 1998, p. 574-588.

FRADIQUE MORUJÃO, A. "A doutrina da intencionalidade na fenomenologia de Husserl: das Investigações Lógica às Meditações Cartesianas". In:

Estudos filosóficos. Lisboa: Imprensa Nacional Casa da Moeda, Vol. 1, 2002 , p. 19-145.

. "Mundo e intencionalidade. Ensaio sobre a noção de mundo na fenomenologia de Husserl". In: Vol. 1, 2002, p. $\overline{173-377 . ~}$

FRAGATA, J. A fenomenologia de Husserl como fundamento da filosofia. Braga: Livraria Cruz, 1956.

HUSSERL, Edmund. Cartesianische Meditationen und Pariser Vorträge. In: Husserliana. Den Haag, Netherlands: Martinuos Nijhoff, Band I, 1973.

. Die Idee der Phänomenologie - Fünf Vorlesungen. In: Husserliana. Netherlands: Martinuos Nijhoff, Band II, 1950.

. Ideen zu einer reinen Phänomenologie und phänomenologischen Philosophie. Erstes Buch: Allgemeine Einführung in die reine Phänomenologie. Halle a. d. S.: Verlag von Max Niemeyer, 1913.

Idées directrices pour une phénoménologie et une philosophie phénoménologique pures (Tome Premier). Paris: Gallimard, 1950. 
C. D. C. Tourinho - A estrutura do Noema e a dupla concepção ...

HUSSERL, Edmund. Ideen zu einer reinen Phänomenologie und phänomenologische Philosophie. Drittes Buch: Die Phänomenologie und die Fundamente der Wissenschaft. In: Husserliana. Hamburg: Felix Meiner Verlag, Band V, 1986.

. Logische Untersuchungen - Erster Band: Prolegomena zur reinen Logik. Halle a. d. S.: Max Niemeyer, 1913.

. Logische Untersuchungen - Zweiter Band, Erster Teil: Untersuchungen zur Phänomenologie und Theorie der Erkenntnis. Halle a. d. S.: Max Niemeyer, 1913.

THOMAS AQUINATIS. Quaestiones disputatae de veritate. In:

Roma: Iussu Leonis XII P. M. Edita, Tom. XXII, Vol. I, Fasc. 2., 1970. Opera omnia.

TWARDOWSKI, K. Zur Lehre vom Inhalt und Gegestand der Vorstellungen. Eine psychologische Untersuchung. Wien: A. Hölder, 1894 (Neudruck: München-Wien: Philosophia Verlag, 1982).

WOLENSKI, J. “Kazimierz Twardowski 1866-1938”. In: CRAIG, E. (ed.). Routledge Encyclopedia of Philosophy. London: Routledge, Vol. 9, 1998, p. 507-509.

\section{Endereço postal:}

Rua Maria Izabel Bolckan - Qd. 65 - Lt. 05 n. 307

Loteamento Maravista - Bairro Itaipú

24342-330 Niterói, RJ, Brasil

E-mail: cdctourinho@yahoo.com.br

Data de recebimento: 15/07/2013

Data de aceite: 10/08/2013 